\title{
BARREIRAS À AMBIÇÃO E À REPRESENTAÇÃO POLÍTICA DA POPULAÇÃO LGBT NO BRASIL
}

\author{
BARRIERS TO THE AMBITION AND POLITICAL \\ REPRESENTATION OF THE LGBT POPULATION IN BRAZIL
}

\begin{abstract}
Resumo
O presente artigo tem por objetivo refletir sobre as barreiras que impedem ou dificultam o desenvolvimento da ambição política entre a população de lésbicas, gays, bissexuais, travestis e transexuais (LGBT) no Brasil para a disputa de cargos políticos no Estado. Para tanto, desenvolvo, por meio de uma pesquisa bibliográfica, um conjunto de reflexões sistematizados em três seções: a primeira discute o conceito de representação política, a segunda explora trabalhos que explicam os fatores para a sub-representação política de mulheres como indícios para a exclusão política de LGBT e a terceira e última seção analisa as barreiras que obstaculizam o desenvolvimento da ambição política e promovem a ausência do segmento LGBT nas esferas representativas brasileiras.
\end{abstract}

Palavras-chave: Democracia. Representação Política. Política de Presença. Diversidade Sexual. Movimento LGBT.

\begin{abstract}
The present paper has the objective of reflecting upon to think about the barriers that prevent or hamper the development of the political ambition between the lesbian, gays, bisexuals and transgenders (LGBT) population in Brazil to dispute political offices in the State. Therefore, I develop, through a bibliographic research, a set of thoughts systematized in three sections: the first one discusses the concept of political representation, the second explores works that explain the factors for the political subrepresentation of women as indications for the political exclusion of LGBT and the third and last section analyses the barrier that difficult the development of political ambition and promotes the absence of LGBT segment in brazilian representative spheres.
\end{abstract}

Keywords: Democracy. Political Representation. Presence Policy. Sexual Diversity. LGBT Movement. 


\section{Introdução}

Embora distintos e complexos, democracia e representação política são conceitos bastante implicados na medida em que os regimes democráticos ocidentais tem buscado, sem sucesso, diga-se, por intermédio da representação, efetivar o governo do povo. A representação surge como mecanismo alternativo à impossibilidade de reunir, na sociedade de massas, todos os cidadãos e cidadãs para discutir e decidir sobre os diferentes interesses que circulam nas nações e comunidades.

No entanto, nos regimes democráticos, é cada vez mais perceptível a super-representação de segmentos e interesses em detrimento de grupos excluídos das instituições representativas liberais. É possível dizer que trabalhadores/as, mulheres, população negra e lésbicas, gays, bissexuais, travestis e transexuais (LGBT), só para citar alguns grupos, são obstados de ocupar espaços de poder tanto pela dinâmica da exclusão social quanto pelos filtros institucionais que tendem a reproduzir as desigualdades sociais na esfera pública e na política eleitoral.

Esse cenário desigual resulta não apenas em sistemas políticos anômalos, ineficientes e incapazes de responder aos anseios da população como também em sentimentos de frustração coletiva com o funcionamento das nossas instituições, além da descrença na política como instrumento de transformação social, de mediação dos conflitos de interesses e de conquista de direitos.

Em face de as instituições representativas estarem ocupadas basicamente por homens, ricos, brancos e heterossexuais que não representam a pluralidade e a diversidade de sujeitos, pensamentos e interesses do povo brasileiro, a luta política tem se dado por fora das instituições, nas ruas, em diferentes espaços públicos e, também, na esfera privada. De diversas maneiras ${ }^{1}$.

É nesse contexto de fechamento das instituições públicas em todas as esferas, no auge da Ditadura Militar e em meio a práticas higienistas, prisões, torturas e assassinatos políticos que nasce o então Movimento Homossexual Brasileiro (MHB). Segundo Júlio Simões e Regina Facchini,

1 As paradas do Orgulho LGBT são claras demonstrações de um conjunto de pessoas que, sendo pouquíssimo representadas pelas instituições democráticas, utilizam as ruas para vocalizar seus interesses e aspirações.
O desabrochar de um movimento homossexual no Brasil se deu no final da década de 1970, com o surgimento de grupos voltados explicitamente à militância política, formados por pessoas que se identificavam como homossexuais (usando diferentes termos para tanto) e buscavam promover e difundir novas formas de representação da homossexualidade, contrapostas às conotações de semvergonhice, pecado, doença e degeneração (Simões \& Facchini, 2009: 13).

A trajetória do ativismo LGBT no Brasil é permeada por mudanças e reconfigurações substanciais motivadas tanto pelas dinâmicas internas da militância quanto pelos fatores sociais externos, como as próprias reconfigurações do Estado brasileiro ou convenções e tratativas internacionais no âmbito dos direitos humanos LGBT. O fato é que este movimento social, por meio de sua organização social, tem desenvolvido forte incidência política em distintos setores da sociedade (Simões \& Facchini, 2009).

De fato, mais que nunca, é possível vislumbrar a politização das identidades sexuais e de gênero em diferentes campos da sociedade, incluindo a mídia, produtora de visibilidade e de visões de mundo (Butterman, 2012). É importante também reconhecer que a definição de Movimento LGBT também é algo aberto, inconcluso e em disputa, seja dentro do ativismo, seja na academia.

Colling (2015), por exemplo, após realizar estudo com ativistas desse Movimento em países da íberoamérica como Argentina, Chile, Espanha e Portugal, tece um conjunto de características que conformariam o Movimento LGBT e os confrontam com o que ele chama de Ativismos das Dissidências Sexuais e de Gênero ou Ativismos Queer.

De modo resumido, Colling (2015) apresenta a seguinte tipologia acerca das diferenças entre o Movimento LGBT e o Ativismo Queer:

\section{a) O Movimento LGBT:}

- Aposta enfaticamente nas instituições e na conquista de marcos legais como as leis de matrimônio igualitário, de antidiscriminação e de reconhecimento das identidades de gênero. 
- Possui poucas ações que promovam o respeito às diferenças de gênero e sexualidade por intermédio do campo da cultura e apresenta uma percepção restrita sobre o que é o campo da cultura e como ela pode produzir ações políticas que resultem em novas formas de subjetivação.

- Por meio da afirmação das identidades, procura encaixar todas as pessoas não-heterossexuais e não cisgêneras em uma das identidades da sigla LGBT. Parece também haver uma supremacia gay que dificulta a emergência das demandas específicas de outras identidades.

- Considera que para conquistar direitos é preciso aderir a uma heteronormatividade que reifica uma imagem limpa que tornaria a população LGBT respeitável e asseada.

- Se organiza de maneira hierárquica e vertical, estabelecendo presidências e coordenações com pouca troca de lideranças ou, em outras palavras, com a presença permanente de um líder, geralmente gay. Esse coordenador representa oficialmente a entidade, muitas vezes sem consultar sua base (quando existe base).

- Busca incidir politicamente através de manifestações, abaixo-assinados, comunicados à imprensa ou emissão de ofícios a órgãos públicos.

- Expressa-se, nas manifestações, de maneira mais comportada com o uso de cartazes mais palatáveis.

- Atua de maneira menos interseccional e menos crítica ao capitalismo e ao modo como o mercado tem absorvido a pauta LGBT e tem ditado padrões corporais e de comportamento de olho no lucro desse segmento.

\section{b) O Ativismo Queer:}

- Prioriza as estratégias políticas através do campo da cultura mediante produtos culturais por entenderem que os preconceitos nascem na cultura e que a sensibilização via manifestações culturais é mais produtiva. Por isso, lançam mão de performances políticas nas ruas. Além disso, critica a aposta em marcos legais quando estes reforçam normas e disciplinas institucionais sobre as sexualidades e os gêneros.

- Rejeita a noção de que para ser respeitado ou portar direitos é preciso abdicar das singularidades em nome de uma 'imagem respeitável' perante a sociedade heteronormativa. Pelo contrário, procura denunciar como se construiu essa respeitabilidade e o quanto ela é produtora de violências.
- Organiza-se de maneira mais horizontal, recusando a ideia de um líder ou coordenador dirigente que represente a base e valorizando os espaços de assembleia em que são discutidos diferentes temas e deliberados decisões coletivas.

- Lança mão de ações de desobediência civil mais intensas, como por meio da ocupação de espaços públicos ou instituições opositoras como as igrejas, o que lhes expõe a ações repressivas mais severas.

- Nas performances e manifestações de rua, o corpo é bastante utilizado como instrumento da política. Os manifestos, gritos de ordem e cartazes exploram sem pudor a dimensão explícita do sexo e da sexualidade. Possuem então um caráter mais irreverente e menos comportado.

- Engaja-se na construção de uma militância mais interseccional, preocupando-se com opressões e desigualdades que atravessam outros sujeitos e segmentos. É mais crítico em relação ao mercado e ao capitalismo.

É possível notar, portanto, que o Movimento LGBT, assim como os estudos de gênero e sexualidade, se constituem como arenas em disputa de sentidos, projetos, práticas e aspirações sociais. Para efeitos de uma compreensão minimamente consensual, importa entender que o Movimento LGBT é um movimento rico, plural, composto por uma infinidade de sujeitos/as e práticas que visam, de um modo ou de outro, modificar a cultura, efetivar e ampliar direitos e superar o quadro de violências motivadas pela discriminação e ódio contra aqueles/ as que escapam às normas hegemônicas de gênero e de sexualidade, historicamente construídas no tecido social.

Não é por acaso que o ativismo tem
enfatizado a denúncia das violências
específicas contra a homossexualidade.
De modo semelhante à "misoginia" ou o
"machismo", para o caso do movimento
feminista, e ao "racismo", para o caso do
movimento negro, a homofobia aparece
para o movimento LGBT como uma
âncora a partir da qual se procura estruturar
as identidades coletivas associadas ao
movimento (Simões \& Facchini, 2009: 25).

Ao fenômeno do ódio direcionado à população LGBT por muito tempo se nomeou de "homofobia" (Borrillo, 2010). O uso do verbo no passado ocorre porque há uma tendência, cada vez mais assimilada pela 
militância brasileira, em adotar o termo "LGBTfobia"2 para expressar as violências dirigidas contra a população LGBT, tornando o termo mais abrangente e inclusivo. Isso porque a palavra "homofobia" não abarcaria todas as identidades que compõem esse movimento social, reclamação feita em especial pelas lésbicas, travestis e homens e mulheres trans.

$O$ fato é que independente de falarmos em Movimento LGBT ou Ativismo Queer, há uma notável ausência de pessoas, ativistas ou não, não-cisheterossexuais nas instituições representativas. A minha hipótese é que a exclusão social, promovida pela escassez de recursos materiais e simbólicos e pelas diferentes formas de violência, dificultam o desenvolvimento da ambição política entre LGBT, elemento necessário para que as pessoas disputem a política institucional e se apropriem das dinâmicas internas desse campo.

Retomando o ponto central do fechamento das instituições liberais brasileiras a determinados grupos e segmentos sociais excluídos, tenho como problema a seguinte indagação: como a violência LGBTfóbica e as estruturas desiguais da sociedade desmotivam a ambição política da população LGBT e dificultam o acesso à representação política? Como extensão desse problema, tenho como objetivos (i) discutir o conceito de representação política, (ii) explorar trabalhos que explicam os fatores para a sub-representação política de mulheres como pistas e indícios para pensar a exclusão política de LGBT e, por fim, (iii) analisar as barreiras que obstaculizam o desenvolvimento da ambição política e promovem a ausência do segmento LGBT nas esferas representativas brasileiras.

Em termos metodológicos, lanço mão de uma abordagem qualitativa de pesquisa (Creswell, 2007) de tipo explicativo (Gil, 2008) desenvolvida através de revisão bibliográfica. A escolha desse tema, por fim, se deu tanto pela necessária investigação da problemática e seus fenômenos - a ausência de LGBT nos espaços de poder representa uma lacuna acadêmica e social - quanto pela possibilidade de contribuir e estimular o Movimento LGBT brasileiro a disputar a política institucional.

2 Essa nomenclatura, inclusive, foi aprovada pela Plenária Final da $3^{\mathrm{a}}$ Conferência Nacional LGBT, ocorrida em Abril de 2016 em Brasília/ DF, para expressar as violências perpetradas contra a população LGBT.

\section{Notas teóricas sobre Representação Política}

Antes de adentrar no debate sobre os processos de exclusão política de LGBT, investigando as dificuldades para agestação daambição política, na políticainstitucional, cabe apresentar a conceituação clássica de representação política. Apesar de o conceito de representação política remontar à Séculos passados, indicando tratar-se de uma inquietação humana antiga, é Hannah Pitkin em seu livro clássico "O conceito de representação" publicado em 1967 que apresenta uma tipologia moderna da representação política.

A autora se baseia em "Leviatã", obra clássica de Hobbes (1651), para explorar os sentidos históricos que a palavra 'representação' pode significar e explica que a representação é, em síntese, tornar presente o que está ausente (Pitkin, 1967). Assim, ela explora diferentes formas de representação presentes na história como a representação artística, como a teatral ou aquela nas pinturas, para chegar na representação política tal qual entendemos hoje.

Segundo Pitkin (1967), Hobbes diferenciou os sujeitos em naturais e artificiais. As pessoas naturais são aquelas que agem diretamente por si, já as pessoas artificiais atuam em nome de outras, das pessoas naturais. A separação entre pessoas naturais e artificiais é a base para a ideia moderna de representados e representantes, atores da representação política.

Também baseada em Hobbes, Pitkin debate a noção de autorização: o detentor dos atos é o autor, o sujeito que possui autoridade. Na impossibilidade da sua presença direta, o autor transfere a autoridade por meio da autorização ao outro que passa a agir em nome do outro: é o que ocorre, por exemplo, na atividade jurídica quando uma pessoa, pelas suas limitações técnicas do campo jurídico, autoriza que o advogado atue pelos seus interesses.

Assim, Pitkin (1967) distingue a representação em quatro naturezas: formalista, descritiva, simbólica e substantiva. A representação formalista expressa a autorização dos representados ao representante que passa a ser detentor dos direitos de representar os constituintes. É dos debates em torno dos interesses dos representados versus a liberdade dos representantes que surge na teoria política o conceito e a importância da accountability 
que significa a prestação de contas dos mandatários de cargos políticos aos seus eleitores. Contudo, a ênfase na autorização formal dos representantes agirem em nome dos representados, expressa na preocupação sobre as formas de eleição desses representantes e na legitimidade dessa representação, ignorou a qualidade da representação.

Com efeito, temos visto em diferentes países da democracia ocidental um amplo distanciamento dos representantes de seus representados, quando não a ação completamente oposta dos mandatários em relação aos desejos, interesses e aspirações dos eleitores. Esse distanciamento tem levado a cabo diversas crises nos regimes democráticos, expressas nas diferentes manifestações populares que reivindicam não só a melhoria dos sistemas representativos como também uma maior participação direta das decisões que afetam a vida de muitos.

Outra forma de representação abordada por Pitkin (1967) é a representação descritiva que seria nada mais do que um mero espelhamento nas instituições representativas dos representados. Esse tipo de representação é criticado pela própria Pitkin porque a descrição das pessoas na arena política faria perder de vista sobre o conteúdo que se representa, hiper-valorizando a quem se representa. A preocupação excessiva sobre quem é representado sobre o que é representado também prejudicaria a qualidade da representação, a discussão de ideias e a accountability já que não interessaria a ação dos representantes, mas sim quem eles espelham.

A terceira forma de representação, também contestada pela autora, é a representação simbólica (Pitkin, 1967), em que não se exige semelhança ou imagem como em um espelho. Os símbolos só representam algo porque evocam sua referência, não tendo necessariamente conexão óbvia com seus significados. $\mathrm{O}$ foco da representação simbólica é emocional e afetivo, portanto, a avaliação desse tipo de representação não se dá no seu conteúdo, na sua qualidade ou em quem ele representa, mas os símbolos que são representados, o que não é interessante para a apresentação dos interesses dos constituintes.

Pitkin aposta, portanto, na quarta e última forma de representação política que é a chamada substantiva. Pois não é interessante a ênfase em quem se representa, mas nas ideias e interesses que são representadas na esfera pública. Desta forma, os representados terão elementos para avaliar a qualidade daquela representação e manter um vínculo efetivo entre representantes e representados. Aqui tanto a autorização quanto a accountability são valorizadas, pois só com estes dois elementos tanto os representados poderão ter mais segurança de que seus interesses serão valorizados quanto a liberdade dos representantes também estaria assegurada, na medida em que os constituintes são livres para avaliar a atuação do representante, mas não poderão obrigá-los a agir de tal maneira, tolhendo sua liberdade de escolha. É uma relação de equivalência bom para ambos os lados. Assim, Pitkin elege a representação substantiva como a ideal para a representação política. Escolha essa criticada pelas teóricas feministas que vão questionar a ausência e a exclusão de determinados sujeitos e agendas no exercício representativo.

É do pensamento feminista (e da gritante exclusão das mulheres nos espaços de poder) que surge uma revalorização do caráter descritivo da representação defendida como política de presença. Anne Phillips (1998) é uma destacada autora que vai defender a ideia de política de presença, na medida em que não bastaria o sufrágio feminino para incluí-las e promover igualdade política. Mesmo após a conquista do voto estendida às mulheres, a representação política delas permaneceu visivelmente baixa em muitos países. Seria então necessário o desenvolvimento de políticas afirmativas que corrijam tais distorções do sistema representativo. As cotas seriam então uma alternativa a essa exclusão que decorre de desigualdades estruturais das relações entre homens e mulheres. Mas reconhecendo as contradições das políticas de cotas, Phillips não propõe uma substituição da política de ideias pela política de presença e sim uma combinação entre as duas, de modo a qualificar a representação e tornála mais justa. Nesse sentido, a visão de responsividade permanece mantida.

É do acúmulo dessa discussão que Phillips, posteriormente, apresenta a ideia de perspectivas sociais, buscando escapar dos essencialismos identitários (essencialismos estes fortemente criticados nos estudos Queer) de modo a fortalecer a política de presença através da valorização e reconhecimento de experiências que posicionam as sujeitas. Young (2000) explora ainda mais a noção relacional de perspectivas sociais e acrescenta essa noção ao que ela classifica de dimensões da representação: interesses, opiniões e as perspectivas sociais. 
Quando pensamos na população LGBT, problemas mais ou menos semelhantes aos das mulheres se insurgem: a discriminação, a agenda dos direitos sexuais tida como específica e não universal, as questões que diriam respeito à esfera íntima (portanto, privada) e não pública, o descrédito, a desqualificação, a incapacidade, as performances identitárias inadequadas para a arena política ou até mesmo a tentativa de instaurar uma "ditadura gay" em que os pobres heterossexuais terão de suportar a "normalização" de condutas promíscuas, inadequadas, desviantes ou pecaminosas. Sem falar numa espécie de proselitismo homossexual que visa transformar todos e todas, com atenção especial às crianças, em homossexuais e transexuais que darão sequência ao regime colorido. A luta contra a violência e a defesa da igualdade de gênero, compreendida como igualdade substantiva entre homens e mulheres e LGBT e cis-heterossexuais, é vista como uma movimentação para a obtenção de privilégios e superdireitos, afrontando a própria Constituição Federal que propugnaria que todos são iguais perante a lei, ou melhor, que a lei é igual para todos.

No caso da população LGBT, políticas de cotas tornam-se ainda mais complexas dado o terreno arenoso das sexualidades e identidades de gênero. Contudo, advogo que a dificuldade para se pensar políticas de cotas para LGBT no parlamento ou nos partidos políticos não resulte numa conformidade passiva com a exclusão vigente dessas pessoas na política. Campanhas de recrutamento partidário, estímulo à candidaturas e promoção de debates sobre esse tema em diferentes setores da sociedade poderiam produzir ótimas iniciativas em um cenário escasso de ações nessa direção.

\section{Sub-representação política de mulheres: pistas para o segmento LGBT}

A desigualdade política envolvendo lésbicas, gays, bissexuais, travestis e transexuais, assim como mulheres, negros ${ }^{3}$, trabalhadores, entre outros grupos marginalizados, tem origem na fase pré-eleitoral a partir do estrangulamento da produção de ambição política entre a população LGBT que não vê na arena política possibilidades concretas de êxitos eleitorais nem tampouco

3 Para uma discussão sobre as barreiras políticas envolvendo a população negra ver Campos \& Machado (2015). um horizonte de transformações possíveis e alcançáveis a partir de si próprios. Esse é um dos motivos pelos quais o Movimento LGBT criou a categoria de 'aliados' ou 'simpatizantes' nos seus cálculos eleitorais, uma vez que é transferido para quadros políticos heterossexuais, vistos com mais condições de ganhar a árdua disputa eleitoral, o desejo e a tarefa de inserir a agenda LGBT na política institucional.

Para ilustrar isso, recorro a Luis Felipe Miguel e Flávia Biroli, professores e pesquisadores de Ciência Política da Universidade de Brasilia, que dizem: "Embora no nível do indivíduo o não surgimento da ambição política reflita apenas a variação das inclinações pessoais, quando afeta todo um grupo social se torna um índice poderoso da desigualdade política" (2010: 664 e 665). Em outras palavras, é comum que determinadas pessoas não ambicionem a política como uma carreira ou exercício da cidadania, mas não é normal que segmentos constituídos por características comuns não estejam presentes nas esferas de poder.

Antes de adentrar nos fatores que obstaculizam a presença de LGBT nas instituições e minam a produção de ambição política entre eles e elas, me amparo brevemente na experiência e nos estudos que focaram a subrepresentação política das mulheres, considerando que existe um vasto campo de produções que investigaram a situação política delas (além disso, creio que, apesar das diferenças entre a experiência das mulheres e da população LGBT, os fenômenos que afetam as mulheres se aproximam em alguma medida daqueles fenômenos que atingem LGBT, diferentemente da população negra, indígena ou com deficiências, que apresentam outras variáveis).

Um estudo relevante sobre ambição política de mulheres é o que Richard Fox e Jennifer Lawless (2012) realizaram nos Estados Unidos através de questionários aplicados a homens e mulheres de profissões com alto índice eleitoral (Direito, negócios, educação e ativismo). Segundo eles, as diferenças de gênero fundamentais estão situadas na fase do processo pré-eleitoral quando ocorre o surgimento dos candidatos.

$\mathrm{Na}$ seleção de candidatos, as mulheres tem probabilidade menor do que os homens de receber incentivos provenientes de uma fonte política como líderes partidários, por exemplo. Além disso, elas tem menos 
probabilidade do que os homens de se considerarem qualificadas para concorrer a um cargo político. Enquanto que os homens que se julgam pouco qualificados tem muito mais chances de cogitarem disputar eleitoralmente. Outro achado importante dessa pesquisa sobre as barreiras para a participação política delas, se refere à socialização cultural que faz com que as mulheres não se sintam instadas a ingressar na disputa eleitoral (Fox \& Lawless, 2012).

Outro trabalho relevante sobre a situação política das mulheres é o de Luis Felipe Miguel e Flávia Biroli (2010) que buscou condensar três vertentes teóricas explicativas sobre tamanha exclusão. A primeira explora o caráter patriarcal das instituições políticas liberais, a segunda analisa os padrões culturais de socialização que produzem o político como espaço destinado aos homens e inibem o surgimento da ambição política entre elas e, por fim, a terceira vertente expõe as condições estruturais à participação política das mulheres que possuem, geralmente, menos acesso a recursos econômicos e tempo livre em relação aos homens.

Assim, a crítica ao liberalismo ocupa posição central nesse trabalho já que ele praticamente perpassa os problemas tratados nas outras vertentes explicativas. $\mathrm{O}$ ideal liberal é criticado na sua formulação de que todos são livres e iguais e que desfrutam dos mesmos direitos formais. A convivência entre direitos formais e as desigualdades reais sempre coexistiram muito tranquilamente na ótica liberal. Outra crítica feminista ao liberalismo se dirige à separação entre público e privado na medida em que as violências dirigidas às mulheres na esfera doméstica ferem de morte a igualdade na esfera pública, dominada pelos homens. Sem falar das atribuições de gênero em que mulheres são empurradas para tarefas da vida privada e homens são estimulados à participarem da esfera pública, incluindo aí os espaços de poder decisório (Miguel \& Biroli, 2010).

É na socialização cultural, devidamente asseguradas pelas instituições liberais, que mulheres possuem sua ambição política minada em detrimento dos homens que não enfrentam os mesmos constrangimentos de gênero para concorrer a mandatos e cargos eletivos. Uma corrida eleitoral está longe de ser fácil tanto para homens quanto para mulheres, mas é certo que partem de condições diferenciadas e desiguais de concorrência.
As obrigações domésticas, atribuídas às mulheres, assim como em outras carreiras (como a profissional ou acadêmica), impedem ou dificultam uma maior dedicação política, elemento necessário para a vida política que possui uma dinâmica própria. Ou seja, a dupla jornada de trabalho (fora e dentro de casa) prejudica o investimento em carreiras. Sendo assim, as mulheres tendem a introjetar sentimentos de impotência política se afastando de um espaço na qual são refutadas. Nesse sentido, é importante perceber que o desinteresse, a "incompetência" nos assuntos políticos e a ausência de ambição política não são características naturais das mulheres, como é largamente argumentado por políticos homens, mas são produtos comuns de uma exclusão ativamente produzida.

Miguel e Biroli (2010) constatam, ainda, que são necessários três tipos de recursos para a participação política: dinheiro, tempo livre e uma rede de contatos, recursos esses concentrados entre os homens brancos e cisheterossexuais. O tempo livre configura-se como o maior obstáculo à participação política das mulheres interditando o interesse pelos assuntos públicos. É importante ter em mente que não é simplesmente uma questão de tempo, mas de atribuição de determinadas responsabilidades impostas a elas. Essa constatação pode explicar o fato de que muitas mulheres ativas na política herdam um capital político de perfil familiar, oriundo de seus pais, maridos ou outras formas de parentalidade (Miguel \& Biroli, 2010).

\section{Barreiras à Ambição e à Representação Política de LGBT}

Feito uma grande síntese dos trabalhos sobre a ausência das mulheres na política institucional - e com base neles - me volto às especificidades que interditam o desenvolvimento da ambição política entre a população LGBT. O pensamento liberal, calcado na ideia de direitos universais e igualdade formal, sem observar as diferenças que geram desigualdades, atrelado à rígida separação entre público e privado, parece também ser central na conformação da exclusão de LGBT da sociedade e, consequentemente, da política.

O espaço público, à despeito da resistência dos corpos LGBT que desobedecem inúmeras normas e ocupam ruas, praças, parques, etc., tradicionalmente condena manifestações de afeto e de sexualidade entre as pessoas, embora vejamos 
todos os dias, em todos os espaços, casais cis-heterossexuais expressando seu desejo afetivo e erótico publicamente. Isso se estende para as organizações de produção simbólica como a mídia, a educação e outros produtos culturais. O exercício da sexualidade é atribuído à esfera privada na medida em que é concebida como parte do rol da intimidade (junto à higiene pessoal ou as necessidades fisiológicas). O problema é que a esfera privada nos moldes liberais é composta pela família nuclear tradicional, composta por homem, mulher - ambos cis-heterossexuais - e filhos biologicamente gerados.

Nesse sistema dual, LGBT são peças estranhas, anormais e abjetas, tomados como sujeitos promíscuos, imorais ou pecadores. E por suas práticas condenáveis devem pagar um alto preço por suas "escolhas" identitárias. Em outras palavras, devem sofrer uma série de violências como um forte mecanismo pedagógico de repressão e conversão de suas orientações sexuais e identidades de gênero diferenciadas para a norma dominante.

Entendendo esse cenário, não fica difícil de compreender a exclusão de LGBT na arena política e o estrangulamento da ambição política desse público. Primeiro porque é difícil, em um contexto de educação cerceada como o nosso, as pessoas perceberem que a sexualidade e a identidade de gênero, mais do que meras características humanas, são marcadores sociais que definem valores, lugares e desigualdades.

Para a população LGBT em si, situada em culturas cis-heteronormativas, suas identidades e preferências devem ser mantidas na clandestinidade e na intimidade, já que "publicá-las" seria uma exposição vergonhosa, sujeita a violências mais intensas. Assim, politizar a sexualidade é a primeira barreira para tornar a vida mais digna, plena de vivências, o que não é algo exatamente fácil já que não dispomos de políticas públicas sólidas ou uma rede de contatos, incluindo profissionais habilitados, para nos empoderar (pelo contrário, LGBT encontram desde a infância até a vida adulta um conjunto de atores que atuam no sentido de condenar as lesbohomotransexualidades como os pais, parentes, vizinhos, amigos, professores ou colegas de trabalho, todos somados à invisibilidade/ inexistência na mídia, nas religiões, nas legislações, entre outros espaços de formulação simbólica).

A cis-heteronormatividade opera mesmo antes de LGBT pensarem em entrar na política tradicional, desencorajando-os/as a participarem das redes organizadas da militância LGBT, comumente um espaço prévio e uma porta de entrada à política institucional, já que participar desse Movimento é considerado uma exposição de sua intimidade e, por tabela, de pessoas que convivem com você como parentes e amigos.

Por tal razão, a promoção de espaços de participação social voltados para a população LGBT, como os Conselhos e as Conferências de Políticas Públicas de Direitos Humanos LGBT, criados nos anos 2000, revelam-se fundamentais para o exercício da cidadania e da participação política dessa população, uma vez que as instituições políticas tradicionais, como os partidos políticos, os parlamentos e os cargos governamentais, encontram-se impermeáveis à população e a agenda LGBT.

Mesmo superando algumas barreiras à participação política, como a entrada no Movimento ou a presença em fóruns de participação social (com o tema LGBT ou outros), a ambição política é desestimulada pelo próprio campo político com suas regras, dinâmicas próprias, recursos exigidos e culturas masculinizadas/cisheterossexualizadas incrustadas nas instituições políticas.

O primeiro desafio é a entrada nos partidos políticos, também frágeis democraticamente e dirigidos por homens cis-heterossexuais. Além disso, os partidos apresentam em seus programas e projetos conteúdos de base material, priorizando a luta (ou a dominação, no caso do empresariado, latifundiários e banqueiros) de classe, entendida como a questão humana primordial que define as nossas vidas.

Na disputa eleitoral, os partidos tendem a apostar em candidaturas com mais chances de vitória e, nessa sociedade padronizada, homens brancos cis-heterossexuais tem mais vantagens e apelo junto ao eleitorado já que a eles é atribuído o papel de discutir os interesses públicos que serviriam a todos e todas, diferentemente de mulheres e LGBT.

Uma candidatura que apresente a defesa dos direitos LGBT tende a atrair bem menos eleitores do que candidaturas que defendem pautas e agendas mais amplas como a da educação, da saúde ou da segurança. Ou pautas e segmentos que gozam de mais solidariedade social como a das crianças e adolescentes, pessoas com deficiência ou idosas. A agenda política LGBT, em um contexto violento como o nosso, não representa um capital 
político (Bourdieu,1981; 2000) substantivo e interessante a postulantes a cargos públicos. Por isso, é comum vermos candidatos e figuras políticas LGBT defensivamente afirmando que a sua atuação e a sua representação ultrapassam os limites da própria agenda de interesses LGBT e se estende para outras causas.

Há argumentos que dizem que LGBT não vota em LGBT. Isso não é bem verdade, mas também não é uma mentira. Afinal, como que LGBT, inseridos em contextos normativos LGBTfóbicos e alijados da participação política, vão conseguir compreender que se organizar e disputar a política institucional é importante para a conquista de direitos? LGBT também são interpelados pela cultura política que privilegia o masculino como o tipo ideal e naturalmente vocacionado para a política. Em suma, LGBT não veem a si nem a seus pares como potenciais quadros políticos.

O temor de ser ofendido em virtude de sua orientação sexual ou identidade de gênero na vida política (nas campanhas, nos mandatos e em outros momentos característicos dessa carreira) também promovem um afastamento e um obstáculo à produção da ambição política.

O relato de Têko (PHS), prefeito de Itapecerica/ MG autodeclarado gay, ilustra o fenômeno da violência política dirigida contra a população LGBT nessa arena: "sofri muitas humilhações, meu nome foi achincalhado nas redes sociais. Minha voz foi motivo de chacota entre meus adversários. Sofri homofobia e recebi todos os nomes que um ser humano pode ganhar, todas as humilhações"

Posso falar também do caso do prefeito de Lins/ SP, Edgar de Souza (PSDB), que teve cartazes com fotos dele e do seu companheiro espalhados pela cidade com mensagens depreciativas ${ }^{5}$ ou ainda do parlamentar gay campeão de boatos e mentiras difundidas na internet, Jean Wyllys (Psol) que dedica parte do seu mandato a desmentir absurdos atribuídos a ele $^{6}$. Em síntese, não faltam exemplos que demonstram que a política é um

4 http://congressoemfoco.uol.com.br/noticias/“sofri-homofobia-ehumilhacao”-diz-prefeito-gay/. Acesso em: 22/07/2017

5 http://www.huffpostbrasil.com/2017/03/06/este-prefeito-enfrentoua-homofobia-e-se-casou-com-seu-companhei_a_21874326/. Acesso em: 22/07/2017.

6 http://br.blastingnews.com/politica/2016/11/jean-wyllys-lancacampanha-para-desmentir-boatos-sobre-ele-001231949.html. Acesso em: 22/07/2017. espaço hostil para lésbicas, gays, bissexuais, travestis e transexuais no Brasil.

Por fim, o acesso desigual a recursos é outro fator que obstaculiza a presença de LGBT nas instituições políticas. Diferentemente das mulheres, LGBT não enfrenta rigorosamente os padrões que as empurram às tarefas domésticas e ao cuidado (com exceção das lésbicas e mulheres bissexuais, mesmo assim, em alguma medida, a maternidade lhes é negada, o que apresenta diferenças em relação às mulheres cis-heterossexuais). Mas a LGBTfobia disseminada socialmente contribui para a exclusão educacional e mercadológica, dificultando o acesso a recursos econômicos, elemento primordial na disputa eleitoral.

Uma disputa eleitoral, nos moldes como está colocada atualmente no Brasil, já é excludente por si só para muitas pessoas em virtude das exigências econômicas que os candidatos precisam atender. Mas LGBT, além das disparidades econômicas, precisam enfrentar outros fenômenos e barreiras que tornam a corrida eleitoral desigual desde a origem. E muito antes dela, na fase de produção da ambição política, sem a qual se torna inviável a entrada na política.

O uso do nome social para travestis, mulheres transexuais e homens trans se configura como um constrangimento até para meros eleitores e para o simples exercício do voto já que o reconhecimento do nome social ainda vem sendo construindo processualmente no Estado brasileiro e nas instâncias eleitorais, indicando que a igualdade política ainda está longe de ser consolidada no Brasil.

Nessa direção, a democracia, entendida aqui como um regime de igualdade e um conceito em intensa disputa de sentidos, desde a mais elitista até a mais alargada (Dagnino et al., 2006; Miguel, 2014; Miguel, 2016; Santos \& Avritzer, 2003), só poderá ser desfrutada com a possibilidade de todos e todas votarem e serem votados sem constrangimentos, barreiras e impossibilidades de diferentes ordens.

Reformas no sistema político ou adoção de políticas de presença para LGBT e outros grupos subalternizados (cotas, campanhas, etc.), embora sejam muito bemvindas, não resolverão completamente a exclusão política se desigualdades fora da política não forem superadas. É preciso, então, ações combinadas dentro e fora da política 
para edificar uma realidade em que o desejo de participar e de transformar a sociedade pela via da política não sejam destroçados na origem.

\section{Considerações Finais}

Como alternativa a esse cenário desmotivador da participação política de LGBT nas instituições tradicionais, movimentos sociais e o governo federal criaram, juntos, novos canais de interlocução entre a sociedade civil e o Estado a partir do Programa Brasil Sem Homofobia (2004) que, embora fossem entendidos como instituições participativas, possuíam uma inegável face representativa. Me refiro, por exemplo, às três edições da Conferência Nacional de Políticas Públicas de Direitos Humanos $\operatorname{LGBT}(2008,2011,2016)$, à criação do Conselho Nacional LGBT (2010), além de diversas comissões espalhadas pela administração pública federal com a presença da sociedade civil organizada (como o Comitê Técnico de Cultura LGBT do Ministério da Cultura, por exemplo).

Essas instituições participativas tem funcionado, na prática, como instituições representativas (Almeida, 2015) e trabalham no sentido de construir documentos que não só reivindicam ações específicas do Estado como também regulam e orientam serviços públicos e tratamentos diferenciados, ampliando, assim, um conjunto de reconhecimentos estatais e direitos do segmento. Posso citar como exemplo o Plano Nacional de Promoção da Cidadania e Direitos Humanos LGBT (2009) ${ }^{7}$, as resoluções elaboradas pelo Conselho Nacional LGBT que regulam o tratamento de LGBT em privação de liberdade $^{8}$ e nas instituições educativas ${ }^{9}$ ou a pressão pela publicação de decretos da administração pública como a

7 O Plano Nacional de Promoção da Cidadania e Direitos Humanos LGBT foi construído com base nas deliberações aprovadas da I Conferência Nacional LGBT e prevê um rol de políticas públicas a serem desenvolvidas pelo Estado. O documento pode ser lido na íntergra aqui: http://www.arco-iris.org.br/wp-content/uploads/2010/07/ planolgbt.pdf. Acesso em: 10/06/2017.

8 A resolução foi elaborada conjuntamente entre o Conselho Nacional LGBT e o Conselho Nacional de Política Prisional e Penitenciária e pode ser acessada aqui: http://justica.gov.br/seus-direitos/politicapenal/politicas-2/diversidades/normativos-2/resolucao-conjunta-no1-cnpc-e-cncd_lgbt-15-de-abril-de-2014.pdf. Acesso em: 10/06/2017.

9 A resolução pode ser acessada aqui: http://www.lex.com.br/ legis_26579652_RESOLUCAO_N_12_DE_16_DE_JANEIRO_ DE_2015.aspx. Acesso em: 10/06/2017. que reconhece o nome social de travestis e transexuais ${ }^{10}$.

No entanto, apesar de tais avanços nos últimos anos, a ampliação dessas conquistas e o aumento da visibilidade da agenda da diversidade sexual e de gênero na esfera pública suscitou reações conservadores/fundamentalistas (mesmo nos governos petistas esses setores organizados já colocavam em risco as conquistas). Tanto em termos de políticas públicas, como no famoso caso do "kit gay" escolar, quanto do ponto de vista da suspensão de tais resoluções, decretos, portarias, etc. Além disso, apesar de Avritzer apontar uma convivência mais ou menos harmoniosa entre diferentes formas de representação com o reconhecimento de múltiplas soberanias (Avritzer, 2007), o que vimos recentemente foi parte do parlamento brasileiro acusar as instituições participativas de anti-democráticas (na medida em que, segundo esses parlamentares, estariam desconsiderando as instituições representativas tradicionais) e serem cúmplices da tentativa de instauração de um regime "bolivariano" tupiniquim por parte do governo do $\mathrm{PT}^{11}$.

Essa aposta no Poder Executivo produziu aquilo que Berenice Bento chama de "gambiarra legal" (Bento, 2014), ou seja, um conjunto de documentos, normas, portarias, decretos e toda uma parafernália burocrática que busca reconhecer as especificidades da população LGBT em diferentes órgãos públicos sem uma perspectiva universal. Por exemplo, uma universidade pública pode ter publicado um decreto que reconhece o nome social de pessoas trans, mas que serve apenas naquela instituição, o que significa que em outra instituição aquele direito já não será reconhecido. Em suma, o Movimento LGBT no anseio de ampliar direitos, de alguma forma tentou legislar via Poder Executivo e se num primeiro momento tais "legislações" (na verdade atos administrativos) eram precárias, após o golpe parlamentar de 2016, que tem moldado o Estado sob viés conservador-neoliberal, correse o risco de retroceder décadas de avanços.

10 Após cobrança na III Conferência Nacional LGBT, a Presidenta Dilma Rousseff assinou um decreto presidencial autorizando o uso do nome social de pessoas trans no âmbito da administração pública federal, como pode ser lido na notícia: https://noticias.uol.com. br/politica/ultimas-noticias/2016/04/28/dilma-assina-decreto-quepermite-transexuais-usarem-nome-social-em-orgaos-federais.htm. Acesso em: 10/06/2017.

11 Para acompanhar essa tensão entre diferentes instituições representativas, ver a seguinte notícia: http://veja.abril.com.br/blog/ reinaldo/o-decreto-bolivariano-de-dilma-e-a-farsa-dos-conselhos8220-populares-8221/. Acesso em: 10/06/2017. 
Nunca a ausência de lésbicas, gays, bissexuais, travestis e transexuais nos espaços de representação política tradicional foi tão evidente. Afinal, no que concerne à política institucional, apenas no parlamento poderemos aprovar leis que apontem para um horizonte de direitos consolidados e disputar contra grupos e segmentos reacionários a avanços civilizatórios democráticos. Além disso, é injusto, pouco representativo e frouxamente democrático que as nossas instituições representativas sejam ocupadas por homens cis-heterossexuais em detrimento de toda uma diversidade de sujeitos, pensamentos e interesses.

O presente artigo buscou, portanto, evidenciar como a violência e as desigualdades sociais fora das instituições liberais transbordam para dentro das instituições políticas, espelhando as injustiças, distorções e correlações de força no tecido social. E o primeiro elemento observável é a aniquilação da produção de desejo e ambição política entre sujeitos e sujeitas vulneráveis que em face das assimetrias e iniquidades não se veem possibilitados a disputar espaços de poder formais.

É um ataque objetivo das estruturas de poder, do ponto de vista dos recursos desigualmente distribuídos, mas também se trata de um ataque subjetivo que visa reforçar os lugares inferiores de determinados grupos e coletivos. Esse trabalho, portanto, teve um caráter explicativo (Gil 2008), na medida em que buscou denunciar um fenômeno que torna a disputa política desigual e, por conseguinte, torna assimétrica a representação política. Também visa o fomento de uma agenda de pesquisa que investigue os processos de exclusão política da população LGBT na política institucional e no Estado.

\section{Referências}

ALMEIDA, Debora Cristina Rezende de (2015). Representação além das eleições: repensando as Fronteiras entre Estado e Sociedade. São Paulo: Paco Editorial.

AVRITZER, Leonardo. (2007). "Sociedade civil, instituições participativas e representação: da autorização à legitimidade da ação". Dados, n. 50, 3: p.443-464, julset.
BORRILlO, Daniel. (2010). Homofobia: história e crítica de um preconceito. Belo horizonte: Autêntica.

BOURDIEU, Pierre. (1981). "La Représentation Politique: Éléments pour une Théorie du Champ Politique". Actes de la Recherche en Sciences Sociales, n. 36-37: p. 3-24.

O poder simbólico. (2000). Rio de Janeiro: Bertrand Brasil.

BUTTERMAN, Steve. (2012) Invisibilidade vigilante: representações midiáticas da maior parada gay do planeta. São Paulo: nVersos.

CAMPOS, Luis Augusto; MACHADO, Carlos. (2015). "A cor dos eleitos: determinantes da sub-representação política dos não brancos no Brasil". Revista Brasileira de Ciência Política, n. 16, 1: p. 121-151, jan-abr.

COLLING, Leandro. (2015). Que os outros sejam o normal: tensões entre movimento LGBT e ativismo queer. Salvador: EDUFBA.

CRESWELL, John. (2007). Projeto de pesquisa: métodos qualitativo, quantitativo e misto. Porto Alegre: Artmed.

FOX, Richard.; LAWLESS, Jennifer. (2012). Entrando na arena? Gênero e a decisão de concorrer a um cargo eletivo. Revista Brasileira de Ciência Política, n. 8, 2: p. 129-163, mai-ago.

GIL, Antônio Carlos. (2008). Métodos e técnicas de pesquisa social. 6 ed. São Paulo: Atlas.

MIGUEL, Luis Felipe. (2014). Democracia $e$ representação: territórios em disputa. São Paulo: Unesp. (2016). Desigualdades e democracia: o debate da teoria política. São Paulo: Unesp.

MIGUEL, Luis Felipe; BIROLI, Flávia. (2010). "Práticas de gênero e carreiras políticas: vertentes explicativas". Revista Estudos Feministas, n. 18, 3: p. 653-679, set-dez. 
PHILIPS, Anne. (1995). The politics of presence. Oxford: Oxford University Press.

PITKIN, Hannah. (1967). The concept of representation. Berkeley: University of California Press.

SANTOS, Boaventura de Sousa; AVRITZER, Leonardo. (2003). "Introdução: para ampliar o cânone democrático". In: SANTOS, Boaventura de Sousa (Org.). Democratizar a democracia: os caminhos da democracia participativa. 2 ed. Porto: Edições Afrontamento. p. 39-82.

SIMÕES, Júlio; FACCHINI, Regina. (2009). Na trilha do arco-íris: do movimento homossexual ao LGBT. São Paulo: Editora Fundação Perseu Abramo.

YOUNG, Iris Marion. (2000). Inclusion and democracy. Oxford: Oxford University Press.

Data de recebimento: $15 / 8 / 2017$.

Data de aceitação: 20/12/2017. 